\title{
CAss Digital Humanities Feature
}

\author{
An Introduction
}

\author{
Katherine M.H. Reischl \\ Princeton University, Princeton, NJ, USA \\ kreischl@princeton.edu
}

As we open 2021 still in our virtual isolation, I write to introduce myself as the new co-editor-in-chief for Canadian-American Slavic Studies. Each new year, and each introduction of a new editor, opens opportunity for retrospective evaluation and optimistic speculation, the latter of which I think is needed more than ever. I could not be more delighted to join the journal and its diverse platform of research in Russian, Eurasian, and Eastern European history, religion, politics, and cultural studies.

As Russian political tensions unfold on local and global stages in this everevolving time of crisis, the need for response from our field could not be more urgent. Over the last fifteen years, Slavic Studies has met the need to expand its scope of geographic coverage in no small measure, from Eurasia to Central Europe. Our field has also diversified in its interdisciplinary representation, growing from philological to intermedial and transnational studies. We must take this opportunity to ask: how can we as diverse humanists - historians, literary scholars, linguists, anthropologists - bring our wealth of expertise to the present, to shifts in the shape of information at the meeting points between emerging media and new crises? Our journal offers one place. On the pages of CASS, original scholarship and timely book reviews offer meeting points between those approaches which dynamically define and redefine our field.

In my first contribution to CASs, I aim to highlight another place wherein our scholarship is being made and tested: the digital interfaces that define not only our scholarship and research, but global citizens' everyday lives. Digital Humanities - the broad umbrella that includes digital archives, large- and small-scale data-driven analysis of corpora, and new approaches to digital pedagogy - represents a laboratory of collaboration and connection not available in traditional scholarship. Slavic Digital Humanities, moreover, may provide platforms and visibility for projects across disciplines, making room to better represent the larger concerns of the field, including the diminution of fund- 
ing and allocation allotted to projects focusing on Eastern Europe outside the Russian context - an issue addressed in our first Digital Humanities Feature, authored by Jessie Labov of Central European University.

In coming issues of the journal, we hope to not only highlight emerging and ongoing projects, but to publish peer-reviewed articles dedicated to research in the field of Slavic Digital Humanities, broadly construed. DH opens a space to consider works in progress, "failed" approaches to material analysis or machine learning, and to connect scholars and projects in our field in new and nimble ways. The shape of these publications should be as flexible and open as the projects themselves. We seek to make available our data and materials such that new generations of scholars might connect, reconnect, and remake them, shaping the next era of Slavic Studies.

This endeavor is further supported by the ASE EES-affiliated Slavic DH group, made up of research scholars, graduate students, digital librarians, and DHfocused staff from institutions in Europe, Russia, and North America (https:// slavicdh.aseees.hcommons.org/about/). 